\title{
Diagnóstico de propriedades leiteiras em regime de agricultura familiar no município de Ponto dos Volantes (MG)
}

\author{
[Diagnosis of dairy farms under family farming regime in the municipality \\ of Ponto dos Volantes (MG)]
}

\section{"Artigo Científico/Scientific Article"}

\author{
Gilson Chaves de Aguilar ${ }^{1}$, Marcos Aurélio Lopes ${ }^{2 *}$, Milton Ghedini Cardoso ${ }^{2}$
}

\author{
${ }^{1}$ EMATER-MG, Ponto dos Volantes, MG, Brasil. \\ ${ }^{2}$ Departamento de Medicina Veterinária, Universidade Federal de Lavras, Lavras-MG, Brasil. \\ *Autor para correspondência/Corresponding author: E-mail: malopes@dmv.ufla.br
}

\begin{abstract}
Resumo
Com o objetivo de conhecer a realidade da pecuária bovina leiteira do município de Ponto dos Volantes, MG, foi realizado um diagnóstico em 30 propriedades produtoras de leite. A pesquisa foi realizada entre os meses de fevereiro e junho de 2016, utilizando um formulário composto por 151 perguntas abertas, em que foram analisados dados básicos da propriedade como: características dos produtores, média produtiva do rebanho, tipo de manejo praticado, uso e ocupação do solo, capacidade operacional da propriedade e as receitas e despesas proporcionadas pela atividade. Com o resultado da pesquisa, não foi possível encontrar índices produtivos e reprodutivos seguros; a falta de escrituração zootécnica não permitiu conhecer a realidade numérica das propriedades. No entanto, possibilitou conhecer iniciativas dos produtores em estabelecer melhor convivência com a seca, como a introdução de novas culturas, de raças adaptadas à região, conservação de alimentos volumosos, melhor uso da água e introdução de sistemas de irrigação.
\end{abstract}

Palavras-chave: agricultura familiar; bovinocultura leiteira; índices técnicos.

\begin{abstract}
In order to know the reality of the dairy cattle production of the municipality of Ponto dos Volantes, Minas Gerais, a diagnosis was conducted on 30 dairy farms. The survey was conducted between February and June of 2016, using a form composed of 151 open questions, in which basic data of the farm such as: characteristics of the dairymen, the mean yield of the herd, type of management practiced, use and occupation of the soil, operational capacity of the farm and the revenues and expenses provided by the farming were analyzed. Based on the results, it was not possible to find safe production and reproductive indices; the lack of animal performance recordings did not allow us to know the numerical reality of the farms. However, it made it possible to know farmers' initiatives in establishing better coexistence with drought, with the introduction of new crops, breeds adapted to the region, conservation of roughages, better use of water, and introduction of irrigation systems.
\end{abstract}

Keywords: family farming; dairy cattle production; technical índice.

\section{Introdução}

O município de Ponto dos Volantes está localizado na região Nordeste de Minas Gerais, no Médio Jequitinhonha, região que sofre muito em consequência das variações climáticas, estiagens prolongadas, irregularidades das chuvas; motivos pelos quais não existe uma atividade agropecuária específica de grande expressão. A agricultura familiar desempenha um papel de grande importância social, detendo $79 \%$ dos estabelecimentos rurais do Estado de Minas Gerais e ocupa $62 \%$ do pessoal no meio rural (França et al., 2009). No município, esse papel é ainda maior, sendo que $91 \%$ das propriedades rurais são da 
agricultura familiar, de acordo com o último censo agropecuário (IBGE, 2006).

A pecuária bovina pode ser considerada a principal atividade do município, que possuía cerca de 350 produtores, sustentados pela produção de leite, seja como atividade principal ou complementar. No entanto, para a maioria, essa atividade é tratada com muito improviso, ao "rumo", contribuindo para uma baixa renda dos produtores e baixa produtividade dos animais. Ter controle adequado e possuir um sistema de custo de produção de leite que gere informações para a tomada de decisões rápidas e objetivas são fundamentais para o sucesso da empresa (Santos e Lopes, 2014). Assim, produtores e técnicos devem estar atentos para estimar os índices e identificar aqueles que apresentam maior desvio em relação a uma situação desejável afetando a rentabilidade da atividade, identificando os pontos de estrangulamento, maximizando a produção e minimizando os custos (Lopes et al., 2009a).

Objetivou-se, com este trabalho, realizar o diagnóstico de propriedades leiteiras, no que diz respeito a aspectos relacionados à produção de leite e identificar as práticas zootécnicas que tem dado resultado na região.

\section{Material e Métodos}

A abordagem da pesquisa é do tipo qualitativa (Bryman et al., 2008; Creswell, 2013) e o instrumento de coleta de dados consistiu na aplicação de um formulário semi estrtuturado, em 30 propriedades do município de Ponto dos Volantes, região Nordeste de Minas Gerais, dos quais $97 \%$ são agricultores familiares que acessaram o Programa Nacional de Fortalecimento da Agricultura Familiar (PRONAF) e 3\% médios produtores que acessaram o Programa Nacional de Apoio ao Médio Produtor (PRONAMP). A pesquisa foi realizada entre os meses de fevereiro e junho de 2016.

As propriedades analisadas foram escolhidas utilizando-se amostragem não probabilística por julgamento, levando-se em consideração os seguintes critérios: disponibilidade e qualidade de dados zootécnicos e financeiros; consentimento e interesse do pecuarista na realização da pesquisa e facilidade de acesso por parte do pesquisador às fontes de evidências (Lopes et al., 2015).

O formulário foi composto por 151 perguntas abertas, em que foram analisados dados básicos da propriedade (localização, área, nome), os atores envolvidos na atividade, o tipo de manejo aplicado ao rebanho leiteiro, o uso e ocupação do solo, a existência de máquinas e equipamentos, a composição do rebanho e as receitas e despesas da atividade.

\section{Resultados e Discussão}

O levantamento dos dados demonstrou que $60 \%$ dos produtores residem na propriedade e $40 \%$ residem na zona urbana ou em aglomerados (povoados e vilas) próximos de suas propriedades. Esse quadro vem se alterando nos últimos anos. $\mathrm{Na}$ pesquisa de Zoccal et al. (2005), 70\% de produtores viviam na propriedade rural. O envelhecimento da população rural fez com que muitos se mudassem para a cidade. Segundo Mera e Mielitz Netto (2014), os problemas de saúde, as limitações de transporte, a distância dos recursos sociais e de saúde, dentre outras dificuldades, foram sentidas com maior intensidade na população de idosos e contribuíram para a migração para as cidades. O aumento dos índices de violência no campo, como assaltos à pessoa física e equipamentos, também tem contribuído com essas migrações.

Dentre os produtores entrevistados, 93\% exploram a propriedade própria e os outros $7,0 \%$ exploram a propriedade da família como arrendatários ou parceiros. As propriedades exploradas possuem, em média, 129,85ha, sendo o percentual para propriedades com até 49ha, 5099ha, 100-260ha e acima de 260ha, de 36,7\%; $30 \% ; 26,7 \%$ e $6,6 \%$, respectivamente.

Apesar da importância de se fazer a escrituração zootécnica e econômica da atividade, somente um produtor possui boa escrituração de sua atividade. Os resultados evidenciam que, dos produtores entrevistados, somente 33,3\% registraram a data do parto das vacas. Destes, somente um produtor $(3,3 \%)$ fez uma análise do que registra, no sentido de conhecer seus índices produtivos e reprodutivos. Os demais, 96,7\% anotam por anotar e é impossível obter qualquer índice, uma vez que outros registros como data de cobertura, data de secagem, controle leiteiro e a anotação de despesas e receitas não são registrados. Segundo Resende et al. (2016), conhecer índices da atividade, que são importantes como determinantes da lucratividade, tem uso prático, principalmente em propriedades com escrituração contábil falha ou inexistente.

A pesquisa revelou uma situação crítica para os produtores. A produção de leite, com média geral de 82,33 L/produtor/dia, onde 40\%; 20\%; $26,7 \%$ e $13,3 \%$ produziam, respectivamente, até 50 
L, 50-99 L, 100-149 L e acima de 150 L. A produtividade diária média das vacas em lactação foi de 2,84 L; bem abaixo dos 7,95; 10,94 e 12,15 L/vaca/dia encontrados por Lopes et al. (2010), Ferrazza et al. (2015) e Moraes et al. (2016), respectivamente, em sistema de produção de leite com uso exclusivo de mão de obra familiar. A baixa produtividade, observada na pesquisa, é o reflexo da extensa área de pastagem degradada existente e da baixa capacidade de suporte das forrageiras. Na pesquisa de Lopes et al. (2008a), constatou-se que os pecuaristas poderiam otimizar o uso da terra, em média, $39,75 \%$, bastando adotar um manejo adequado das pastagens. Considerando que a remuneração da terra é um importante componente do custo total de produção de leite (Lopes e Carvalho, 2000), uma vez aumentada a taxa de lotação, o fator de produção terra pode ser otimizado, reduzindo o custo de produção e aumentando a rentabilidade.

Segundo Resende et al. (2016), entre os principais indicadores de desempenho, que determinam a lucratividade de fazendas leiteiras, estão relacionados ao volume de produção de leite, dentre eles: produção de leite por vaca e produção de leite por mão de obra. Esta relação está ligada a diluição dos custos fixos. Custos fixos são aqueles associados às despesas consideradas fixas, sendo independentes da quantidade produzida, e, em particular, eles têm que ser pagos se a firma produz ou não o produto (Varian, 1993). Outro fator, que impacta na rentabilidade, é a receita com a venda de leite, em que a escala de produção proporciona variações crescentes, no preço recebido pelo leite (Lopes et al., 2006; Lopes et al., 2008b).

A solução buscada por alguns é a exploração, das áreas de pastejo, utilizando o pastejo rotacionado, adubado e irrigado, que é para poucos, em função da falta de córregos perenes e secagem completa dos intermitentes. Como a crise hídrica é considerável e com o volume dos córregos perenes cada dia menor, aqueles que adotaram o sistema de irrigação de suas pastagens sofreram a pressão da comunidade pelo uso da água disponível que já está fazendo falta para a irrigação de suas lavouras.

A baixa eficiência produtiva também pode ser explicada pela ineficiência reprodutiva do rebanho. A eficiência reprodutiva afeta diretamente a composição e a evolução do rebanho e, consequentemente, a rentabilidade da atividade leiteira (Lopes et al., 2009b). No presente estudo, somente $24,5 \%$ dos animais das propriedades estavam em lactação. No estudo de Resende et al. (2016), as propriedades que possuíam em média $32,7 \%$ dos animais em lactação possuíam renda líquida anual positiva. Entre os animais em fase adulta, somente 53,6\% estavam em lactação, inferior aos 74,7\% encontrado por Resende et al. (2016) nas fazendas com renda líquida anual positiva.

A falta de controle de receitas e despesas não permitiu conhecer a renda de nenhum dos produtores. Segundo Lopes e Carvalho (2000), a necessidade de analisar economicamente a atividade leiteira é extremamente importante, pois, por meio dela, o produtor passa a conhecer com detalhes e a utilizar, de maneira inteligente e econômica, os fatores de produção (terra, trabalho e capital). Neste estudo, o controle das despesas é baseado na memória e as receitas se limitam ao que entra no final do mês com a venda do leite. A renda demonstrada não condiz com a realidade, mas, para haver um norteador da receita, em relação à produção de leite, foi tomada, como base, a produção atual, transformada em média/dia e o preço de leite em $\mathrm{R} \$ 1,05$ praticado no município. Observou-se que $10 \% ; 50 \% ; 26,7 \%$ e $13,3 \%$ dos produtores possuíam, respectivamente, renda de um, um a três, três a cinco e acima de cinco salários mínimos, com a atividade leiteira. Uma opção para aumentar a renda dessas propriedades, seria por meio da venda de animais. Lopes et al. (2009b) demonstraram que fazendas com rebanho estabilizado e com intervalo de partos de 12 meses podem ter um incremento na renda, com a venda de animais, na ordem de $25 \%$. Porém, para que isso ocorra, as propriedades estudadas precisam melhorar a sua eficiência reprodutiva. Apesar das dificuldades e do baixo desempenho demonstrado pelos agricultores frente aos números apresentados, inúmeros esforços estão sendo feitos pelos produtores parra melhorar a situação. Dentre eles pode-se destacar:

a) Exploração da energia do sol, para produção de feno em secador solar lonado, sendo usado milho (Zea mays), capim camerum (Pennisetum purpureum Schumac) e mandioca (Manihot esculenta Crantz), afim de enfrentar os períodos prolongados de estiagem;

b) Implantação de culturas que suportam melhor a baixa pluviosidade da região, como a palma forrageira miúda (Nopalea cochenilifera). A região oferece boas condições para o desenvolvimento vegetativo dessas plantas. Essa variedade possui alto potencial produtivo de 
massa verde, em plantios adensados, podendo chegar a 639 ton/ha/ano (Silva et al., 2014).

c) Construção de lagoas e barragens de águas para permitir a implantação de sistemas de irrigação.

d) Implantação de sistemas de irrigação por gotejamento, para aumentar as produtividades das pastagens e das lavouras de milho, cana de açúcar e capineiras, com uso mais eficiente da água.

e) Aquisição de animais de raças mais adaptadas a regiões semiáridas, a exemplo da raça Sindi.

Com esta pesquisa, não foi possível encontrar índices produtivos e reprodutivos seguros. A falta de escrituração zootécnica não permitiu conhecer a realidade numérica das propriedades.

\section{Conclusão}

Pode-se afirmar que as crises levam os homens a refletir sobre suas ações. Apesar dos índices produtivos e reprodutivos do rebanho de Ponto dos Volantes, Minas Gerais, não trazerem bons exemplos, as iniciativas dos produtores refletem o contrário. Eles já perceberam a necessidade do cultivo mínimo, do uso racional da água, cultivo de plantas adaptadas, seleção de animais melhores e introdução de novas raças.

Hoje, o maior desafio é aprender a conviver com a seca, controlar custos e fazer o controle zootécnico do rebanho. Conhecer a realidade da porteira para dentro, com certeza, facilitará, e muito, a permanência do produtor na atividade. Mas, para isso, é urgente adotar uma postura mais profissional, passando a enxergar a propriedade como uma empresa e não como uma simples "roça", para ser visitada aos finais de semana. Por meio desta pesquisa, foi possível verificar que quanto mais adversa for a situação, melhor deve ser a capacidade de gestão do produtor.

\section{Conflito de Interesse}

Os autores declaram não existir conflito de interesse.

\section{Agradecimentos}

Os autores agradecem à EMATER - MG, por ter possibilitado a realização desta pesquisa, e ao CNPq pela concessão de bolsa de produtividade ao segundo autor.

\section{Referências}

Bryman, A.; Becker, S.; Sempik, J. Quality criteria for quantitative, qualitative and mixed methods research: a view from social policy. International Journal of Social Research Methodology, 11(4): 261-276, 2008.

Creswell, J.W. Designing a qualitative study. In: Qualitative inquiry and research design. London: Sage, 2013. 42-68p.

Ferrazza, R.A.; Lopes, M.A.; Bruhn, F.R.P.; Moraes, F. Índices de desempenho zootécnico e econômico de sistemas de produção de leite com diferentes tipos de mão de obra. Ciência Animal Brasileira, 16(2): 193-204, 2015.

França, C.G.; Del Grossi, M.E.; Marques, V.P.M.A. O censo agropecuário 2006 e a agricultura familiar no Brasil. Brasília: MDA; 2009. $95 \mathrm{p}$

IBGE - Instituto Brasileiro de Geografia e Estatística. Censo agropecuário. 2006. Rio de Janeiro. Disponível em: <http://www.ibge.gov.br/home/estatistica/economia/agrop ecuaria/censoagro/>. Acesso em: 23 mar. 2017.

Lopes, M.A.; Cardoso, M.G.; Demeu, F.A.; Dias, A.S. Composição de rebanhos bovinos leiteiros: levantamento, estimativa do dimensionamento e da evolução. Boletim de Indústria Animal, 65(2): 167-171, 2008a.

Lopes, M.A.; Dias, A.S.; Carvalho, F. de M.; Lima, A.L.R.; Cardoso, M.G.; Carmo, E.A. Efeito da escala de produção nos resultados econômicos de sistema de produção de leite na região de Lavras (MG) em 2004 e 2005. Archivos Latinoamericanos de Producción Animal, 16: 121-129, 2008b.

Lopes, M.A.; Carvalho, F.M. Custo de produção do leite. Lavras: UFLA, Boletim Agropecuário, 32, 2000. 42p.

Lopes, M.A.; Demeu, F.A.; Santos, G.; Cardoso, M.G. Impacto econômico do intervalo de partos em rebanhos bovinos leiteiros. Ciência e Agrotecnologia, 33(Edição Especial): 19081914, 2009b.

Lopes, M.A.; Dias, A.S.; Carvalho, F. de M.; Lima, A.L.R.; Cardoso, M.G.; Carmo, E.E.A. Resultados econômicos de sistemas de produção de leite com diferentes níveis tecnológicos na região de Lavras, MG nos anos 2004 e 2005. Ciência e Agrotecnologia, 33(1): 252-260, 2009a. 
Lopes, M.A.; Dias, A.S.; Carvalho, F.M.; Lima, A.L.R.; Cardoso, M.G.; Carmo, E.A.do. Efeito do tipo de mão-de-obra nos resultados econômicos de sistemas de produção de leite na região de Lavras (MG) nos anos 2004 e 2005. Revista Brasileira de Agrociência (UFPEL), 16(1-4): 125-132, 2010.

Lopes, M.A.; Lima, A.L.R.; Carvalho, F. de M.; Reis, R.P.; Santos, I.C.; Saraiva, F.H. Efeito da escala de produção nos resultados econômicos de sistemas de produção de leite na região de Lavras (MG): um estudo multicasos. Boletim de Indústria Animal, 63(3): 177-188, 2006.

Lopes, M.A.; Moraes, F.; Carvalho, F.M.; Peres, A.C.C.; Bruhn, F.R.P.; Reis, E.M.B. The effect of technological levels on profits of milk production systems participating in the "full bucket" program: a multicase study. Semina: Ciências Agrarias, 36(4): 2909-2922, 2015.

Mera, C.M.P.; Mielitz Neto, C.G. Envelhecimento dos produtores no meio rural na região do alto Jacuí/RS e consequente migração. Estudos Interdisciplinares sobre o Envelhecimento, 19(3): 758-758, 2014.

Moraes, F.; Lopes, M.A.; Brunhn, F.R.P.; Carvalho, F.M.; Lima, A.L.R.; Reis, E.M.B. Efeito de índices técnicos e gerenciais na rentabilidade da atividade leiteira com diferentes tipos de mão de obra. Archivos Latinoamericanos de Producción Animal, 24(1):29-38, 2016.

Resende, J.C.; Freitas, A.F.; Pereira, R.A.N.; Silva, H.C.M.; Pereira, M.N. Determinantes de lucratividade em fazendas leiteiras de Minas Gerais. Arquivo Brasileiro de Medicina Veterinária e Zootecnia, 68(4): 1053-1061, 2016.

Santos, G.; Lopes, M.A. Indicadores econômicos de sistemas de produção de leite em confinamento total com alto volume de produção diária. Ciência Animal Brasileira, 15(3):239-248, 2014.

Silva, L.M.da; Fagundes, J.L.; Viegas, P.A.A.; Muniz, E.N.; Rangel, J.H.A.; Moreira, A.L.; Backes, A.A. Produtividade da palma forrageira cultivada em diferentes densidades de plantio. Ciência Rural, 44(11): 2064-2071, 2014.

Varian, H.R. Microeconomia: princípios básicos. $2^{\mathrm{a}}$ ed. Rio de Janeiro: Campus, 1993. 380 p.

Zoccal, R.; Souza, A.D.; Gomes, A.T. Produção de leite na agricultura familiar. Juiz de Fora: Embrapa Gado de Leite, Boletim de Pesquisa, 17. 2005. 20p. 